\title{
Evaluation of Phytotoxic and Clastogenic Potential of Phenolic Pollutant Bisphenol A and its Bioremediated Product in Triticum aestivum, Cicer arietinum and Allium cepa
}

\author{
Janki Trivedi* and Urvish Chhaya \\ Department of Microbiology, N.V. Patel College of Pure and Applied Sciences, \\ Vallabh Vidyanagar, Anand, Gujarat, India \\ *Corresponding author
}

\section{A B S T R A C T}

\section{Keywords}

Bisphenol A, Phytotoxicity, Genotoxicity, Bioremediation, Trametes versicolor laccase

\section{Article Info}

Accepted:

07 January 2021 Available Online: 10 February 2021
Bisphenol A (BPA) is a known Endocrine disrupting chemical. It affects plant growth by changing the ratio of endogenous growth and stress hormone levels. In the present study, BPA bioremediation was carried out using nanoemulsion based organogel comprising Trametes versicolor (TV) laccase enzyme. The effect of BPA and its bioremediated products was studied on two different plant species, i.e. Wheat (Triticum aestivum) and Chickpea (Cicer arietinum) grown hydroponically. Genotoxicity of BPA was assessed by Allium cepa assay. BPA showed inhibition effect on chickpea in dose dependent manner and completely inhibited its germination at $100 \mathrm{mg} / \mathrm{L}$ concentration. It affected growth of wheat and chickpea seedlings in early stages of development at $25 \mathrm{mg} / \mathrm{L}$ concentration. There were significant phytotoxic effects caused by BPA in terms of reduction of root and shoot length with respect to both plant species. BPA exposure $(25 \mathrm{mg} / \mathrm{L})$ for 21 days resulted in reduction in wet weight and dry weight of seedlings of wheat and chickpea. However, there were no toxic effect TV laccase organogel treated BPA $(100 \mathrm{mg} / \mathrm{L})$ was observed in both plant species. The seedling grown hydroponically in treated BPA solution has shown similar growth indices as control (no BPA), which indicates its reduced phytotoxicity. Reduction in mitotic index and chromosomal aberrations in Allium cepa root tip cells suggest genotoxicity of BPA. The bioremediated products of BPA showed no cytotoxic effects indicating elimination of its clastogenic effect on plant cells, that may be due to structural modification of BPA mediated by TV laccase.

\section{Introduction}

Bisphenol A (4,4 propane-2,2-diyl) diphenol commonly known as BPA is a phenolic plasticizer used as a hardening agent in the making of polycarbonate and resin. These materials are widely used in production of plastic bottles including baby bottles, food cans, electronics items, and digital media equipment (Mikolajewska et al., 2015). The global BPA consumption was estimated 7.7 million metric tons in 2015, and its expected compound growth rate is $4.8 \%$, that means its consumption can reach up to 10.6 million tons 
in 2020. Asia Pacific has largest BPA market (53\%), the production and consumption of BPA is gradually increasing in Asian countries, especially in China. Western Europe and USA are second largest consumer with 36\% market share (Industry Experts, 2016).

BPA is one of the organic micropollutant classified under endocrine disrupting chemicals (EDC). It imitates biological activity of natural hormones, occupy its receptors, or interfere with normal hormonal system and cause various health issues in humans. BPA binds weakly to estrogen receptor and shows estrogenic effects (Kwak et al., 2001). BPA is detectable in human serum, urine, secretary body fluids of animals like breast milk, amniotic and follicular fluid (Lee et al., 2018). The mass production and frequent use of BPA has resulted in its sustained release and thus it became omnipresent in the natural environment. Its presence has been detected in surface water, industrial run off, ground water and landfill leachates at concentration ranging from $21 \mu \mathrm{g}$ to $17.2 \mathrm{mg} / \mathrm{L}$. (Crain et al., 2007). Rivers and lakes, present near industrial areas, are heavily contaminated by BPA. Aquatic communities of fish, amphibian, benthos, plankton, molluscs, primitive sponges, and algae residing in water bodies are adversely affected by continuous exposure of BPA (Mihaich et al., 2018). In similar manner, plants and crops may get exposed to this chemical because of fields irrigated with landfill leachate discharge, sewage sludge and wastewater effluent containing BPA (Corrales et al., 2015).

BPA was able to produce morphological and physiological abnormalities in broad bean, tomato, durum wheat and lettuce seedling at concentration of 10 and $50 \mathrm{mg} / \mathrm{l}$ during 21days of exposure in hydroponics. In tomato and broad bean seedlings BPA accumulation was noted at various extent. Moreover, BPA showed clastogenic effect in durum wheat seedlings (Ferrara et al., 2006). This environmental pollutant negatively affects soybean seedling root growth at concentration of 17.2 and $50 \mathrm{mg} / \mathrm{L}$ (Sun et al., 2013). BPA inhibited germination and early seedling growth of Arabidopsis thaliana in dose dependent manner (Pan et al., 2013). It also reduces flowering in Arabidopsis thaliana due to overproduction of auxin resulted from the altered gene (ACS11) expression at very low concentration $(0.2 \mu \mathrm{M})$ (Frejd et al., 2016). Genotoxic effects of BPA are also reported in Allium cepa exposed to 50, 100, 150 and 200 $\mathrm{mg} / \mathrm{L} \quad \mathrm{BPA}$ concentration including chromosomal aberration observed in root tip cells (Jadhav et al., 2012). Chromosomal abnormalities and reduced mitosis are the most prominent effect reported in many plant species due to BPA exposure, its negative effect on mitosis/cytokinesis is a result of disturbed microtubule organisation (Admakis et al., 2019). As plants are primary producers in food chain, effect of any contaminant or chemical on plant systems will directly affect all consumers and decomposers depending upon them and thus it has widespread effect on entire ecosystem. However, effect of BPA on plant system has not been explored as much as in animal system.

Bioremediation of BPAis possible through various routes including ozonation, enzymatic oxidation, photooxidation, chemical oxidation, solvent extraction, membrane filtration, phytoremediation, and biodegradation. Biodegradation using Trametes versicolor has been successfully employed in reverse micelles system composed of sodium bis sulfosuccinate and isooctane. Non- aqueous catalysis is advantageous to aqueous catalysis because of hydrophobic BPA is freely soluble into nonpolar solvent isooctane (Chhaya and Gupte, 2013). This micellar solution can be 
entrapped into organogel using gelator molecule such as calcium alginate. In present study, BPA and its treated product obtained by catalysis using calcium alginate nanoemulsion based organogel were subjected to study their phytotoxic and clastogenic effects.

\section{Materials and Methods}

\section{Chemicals and Seed material}

4,4'-(propane-2,2,-diphenol) (Bisphenol A) was procured from LobaChemie (Mumbai). Purified Laccase from Trametes versicolor and Bis (2-ethylhexyl) sulfosuccinate sodium salt was purchased from SIGMA life sciences. Organic solvents used in this study were of analytical grade purchased from Merck Chemicals. All other chemicals used in this study were of analytical grade having highest possible purity.

Economically relevant monocotyledon species wheat and the dicotyledon species chickpea were selected for this work. Seeds were surface sterilized by treating them with sodium hypochlorite $(0.1 \mathrm{M})$ solution for five minutes followed by normal distilled water wash for three times.

\section{Growth medium and condition}

Hoagland's basal salt medium was used for hydroponics studies. The composition of the medium was as follow.

Potassium phosphate monobasic-136.03 $\mathrm{mg} / \mathrm{L}$; Potassium chloride-372.70 mg/L; Calcium chloride. $2 \mathrm{H}_{2} \mathrm{O}-554.90 \mathrm{mg} / \mathrm{L}$; Magnesium sulphate-240.33 $\mathrm{mg} / \mathrm{L}$; Manganese chloride. $4 \mathrm{H}_{2} \mathrm{O}-1.81 \mathrm{mg} / \mathrm{L}$; Boric acid-2.86 mg/L; Molybdic acid (sodium salt). $2 \mathrm{H}_{2} \mathrm{O}-0.025 \mathrm{mg} / \mathrm{L}$; Copper chloride$0.045 \mathrm{mg} / \mathrm{L}$; Zinc chloride-0.11 mg/L; EDTA ferric monosodium salt-33.00 mg/L
For each study 15 seeds were taken. Germination condition of $14 \mathrm{~h}$ photoperiod: $10 \mathrm{~h}$ dark was maintained at room temperature.

\section{Dose dependent effect of BPA on chickpea seedlings}

Dose dependent effect of BPA on chickpea was studied by growing them in Hoagland's medium supplemented with various concentrations of BPA ranging from 25, 50, 75 and $100 \mathrm{mg} / \mathrm{L}$. These solutions were prepared by dissolving appropriate amount of BPA in methanol and thereafter added into Hoagland's medium. $0.5 \mathrm{ml}$ of methanol was added to Hoagland's medium served as control. Effect of BPA was noted on various growth indices including germination, root and shoot length.

\section{Bioremediation of BPA using nanoemulsion based Calcium alginate organogel}

The laccase enzyme from Trametes versicolor was entrapped in system comprising surfactant molecule sodium bis (2-ethylhexyl) sulfosuccinate (AOT) and organic solvent 2,2,4-Trimethylpentane (isooctane). The reverse micellar system was prepared by dissolving $6.68 \mathrm{~g}$ of AOT in $100 \mathrm{ml}$ of isooctane $(150 \mathrm{mM})$ by gentle stirring using magnetic stirrer. Concentrated enzyme solution $(5 \mathrm{mg} / \mathrm{ml})$ prepared in buffer $(\mathrm{pH}$ 4.5) was added drop wise into above mentioned micelles system under continuous stirring to achieve nanoemulsion preparation, resulting nanoemulsion was kept at $4{ }^{\circ} \mathrm{C}$ for further use. Nanoemulsion based calcium alginate organogel was prepared using 3\% w/v sodium alginate. Sodium alginate was dissolved in distilled water at $50^{\circ} \mathrm{C}$ under continuous stirring. After complete gelator solubilisation laccase nanoemulsion solution was introduced by maintaining solvent to 
aqueous phase ratio at 10:1. Once homogenization has been achieved, this solution was poured drop wise into $7 \% \mathrm{w} / \mathrm{v}$ calcium chloride solution, maintained at $4{ }^{\circ} \mathrm{C}$ temperature, to get beads of 3-4 mm diameter. The beads were kept at $4{ }^{\circ} \mathrm{C}$ for 24 hours in calcium chloride solution before use. Bioremediation of BPA was carried out for various time interval using prepared beads.

\section{FTIR analysis of BPA and its remediated product}

Chemical characterization of BPA and laccase treated BPA (2hour treatment) was done using Fourier Transform Infrared Spectrometer (FTIR) using Perkin Elmer Spectrum equipped with MIRTGS detector. Samples were prepared by pressed pellet technique using potassium bromide. The pellet was placed in the IR beam using the sample transmission holder. The measurements were carried out in the transmission mode for both sample and spectra were developed by spectrum GX software.

Determining phytotoxic effect of BPA and its bioremediation product on Triticum aestivum and Cicer arietinum

To study phytotoxicity of BPA on wheat and chickpea, seeds were grown into Hoagland's solution having $25 \mathrm{mg} / \mathrm{L} \mathrm{BPA}$ concentration. In similar manner seeds were grown in Hoagland's solution containing $100 \mathrm{mg} / \mathrm{L}$ treated BPA solution to evaluate its phytotoxic effects.

The seeds grown in Hoagland's solution containing $0.5 \mathrm{ml}$ methanol served as negative control. Growth indices were measured on regular time interval of 7 days up to 21 days. Their wet weight and dry weight were determined after 21 days of exposure.

\section{Allium cepa test}

To study cytotoxic effects of BPA Allium сера test was carried out as described by Fiskesjo (2008) with some modifications. Commercially available onion bulbs were purchased from local market. Their outer scales were removed carefully to make apices of root primordia exposed. Onion bulbs were thoroughly washed with tap water to remove soil and debris; their surface sterilization was done using $0.1 \mathrm{M}$ sodium hypochlorite solution. They were washed with distilled water twice. These bulbs were allowed to germinate in distilled water for 24 hours away from direct sunlight. After measuring the root length, they were exposed to various concentration of BPA ranging from 50, 75 and $100 \mathrm{mg} / \mathrm{L}$ and enzyme treated BPA (100 $\mathrm{mg} / \mathrm{L})$ solution. The onion bulbs placed in distilled water served as negative control. Onion bulbs were allowed to germinate in various test solution for 48 hours, after that from each bulb growing root tip (1-2 mm) were selected randomly for microscopic examination. First, the root tips were fixed in the ethanol: glacial acetic acid (3:1, v/v) solution for 2-3 hours at $4{ }^{\circ} \mathrm{C}$. The fixed root tips were hydrolysed in hydrochloric acid (1N) solution for 1 minutes at $60^{\circ} \mathrm{C}$ and then washed with distilled water. Washed root tips were stained by $1 \%$ aceto-orcein stain for 5 minutes. Excess amount of stain was removed, and root tips squash were prepared by placing coverslip over mounted root tip and applying slight pressure. The prepared slides for each exposure medium were observed under the light microscope at 400x magnification to score of mitotic stages and nuclear abnormalities in the interphase cells.

\section{Statistical analysis}

All the experimental data were statistically analysed by two-way analysis of variance (ANNOVA) at $P$ value 0.05 . 


\section{Results and Discussion}

\section{Dose dependent effect of BPA on chickpea seedlings}

Chickpea seeds grown in Hoagland's solution medium having 25, 50, 75 and $100 \mathrm{mg} / \mathrm{LBPA}$ concentration showed difference in their germination rate as compare to seeds grown in control solution without BPA. Dose dependent effect of BPA on chickpea is illustrated in figure 1. Increasing concentration of BPA negatively affects seed germination at concentration of $25,50,75$ $\mathrm{mg} / \mathrm{L}$ concentration and totally inhibits germination at concentration of $100 \mathrm{mg} / \mathrm{L}$. Seed germination was 84,65 and $50 \%$ of control in 25, 50 and $75 \mathrm{mg} / \mathrm{L}$ BPA concentration, respectively.

The effect of BPA treatment of varying concentration on chickpea seedlings, grown for 21 days is presented in Figure 2 and 3. It is evident from figure 2 and 3 that BPA more severely affected root than shoot of young seedling. In particular at $50 \mathrm{mg} / \mathrm{L} \mathrm{BPA}$ concentration, root length reduction of $53 \%$ and shoot length reduction of $63 \%$ as compared to control were noted. At higher concentration of BPA $(75 \mathrm{mg} / \mathrm{L})$, root and shoot length reduction of 73 and $67 \%$ as compared to control were observed in present study.

\section{FTIR analysis of BPA and its remediated product}

FTIR analysis of BPA and organogel treated BPA solution showed difference in their infrared spectrum (Figure 4). Spectral analysis of BPA revealed major peak at 3439 which indicate polyphenol stretching, peaks between 2800-3000 (2958, 2924, 2854) suggest $\mathrm{CH}$ and $\mathrm{CH}_{2}$ stretching, which may indicate presence of carbon bonding between two aromatic ring structure. IR absorption peak ranging from 1000-1200 depict C-O (1199, 1093, 1067) stretch of BPA. Treated BPA spectra showed elimination of several peaks found in BPA IR spectra, major difference was found between 2800-3000 band patterns, peaks indicating $\mathrm{CH}$ (2958, 2854) stretching was not found in treated sample spectra which may be due to removal or modification of $\mathrm{CH}$ group found between aromatic ring structure. Another significant difference was found regarding the absence of peak between the range of 1100-1200 indicating C-O $(1195,1155)$ stretching which may be due to the removal of terminal-OH group present in BPA.

\section{Determining phytotoxic effect of BPA and its bioremediation product on Triticum aestivum and Cicer arietinum}

The germination rate of wheat and chickpea seeds were adversely affected by BPA (25 $\mathrm{mg} / \mathrm{L})$ supplemented in growth medium (figure 5). Germination rate was found to be $63 \%$ and $69 \%$ for wheat and chickpea, respectively. Whereas germination rate in control and treated BPA (100 mg/L) solution were almost similar. Moreover, delayed germination and seed blackening was observed in wheat in presence of BPA.

The average root and shoot length of wheat seedlings grown in presence of BPA was severely reduced in comparison with control (figure 6). Most remarkable phytotoxic effect of BPA was observed in wheat especially on root growth then shoot and it was $25 \%$ of the control root growth after 21 days of exposure. The root length of chickpea after 21 days of exposure was also found to be decreased as compare to control, it was $46 \%$ of the control root growth. The shoot length of wheat and chickpea was 70 and $68 \%$ of control after 21 days of growth (figure 7). The seedling grown in treated BPA solution showed shoot length of $90 \%$ in both plant species compared to 
control (no BPA). The root length of $75 \%$ and $84 \%$ of control was recorded in wheat and chickpea seedlings, respectively. Moreover, reduction in wet and dry weight of BPA treated seedling of wheat and chickpea seedling (showed in figure 8 and 9 respectively) also suggest negative impact of this chemical.

\section{Allium cepa test}

Allium cepa test is very useful to assess genotoxicity of environmental contaminant. Onion roots exposed to pollutant BPA pose reduction in their mitotic index and several chromosomal abnormalities significantly at higher concentration. The mitotic index of onion root tip cell was 64, 38 and $20 \%$ exposed to 50, 75 and $100 \mathrm{mg} / \mathrm{L}$ BPA concentration, respectively. Mitotic index of onion root tip cells exposed to treated BPA solution was found to be $92 \%$ of control. The microscopic examination of normal interphase cell and meristematic region of Allium cepa is given in figure 10. Microscopic appearance of observed abnormalities due to BPA exposure is presented in figure 11.

Fig.1 Dose dependent effect of BPA on chickpea germination

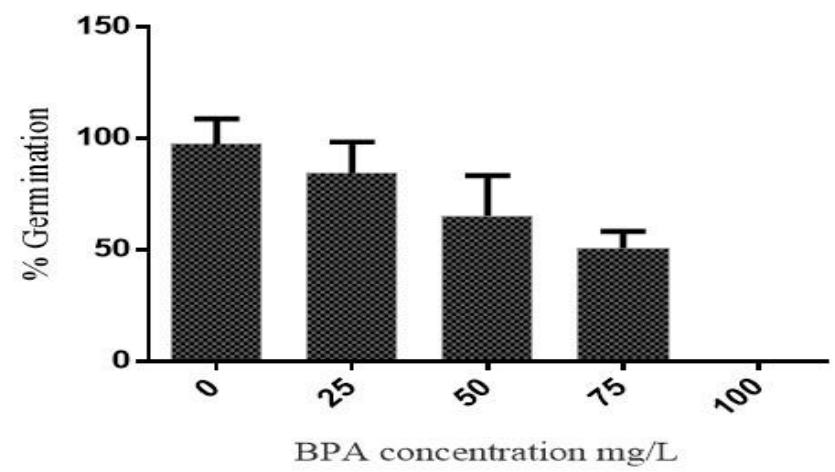

Fig.2 Effect of different concentration of BPA on root and shoot length of chickpea seedling after 21 days of exposure(A) No BPA (B) $25 \mathrm{mg} / \mathrm{L} \mathrm{BPA} \mathrm{(C)} 50 \mathrm{mg} / \mathrm{L}$ (D) BPA $75 \mathrm{mg} / \mathrm{L}$ (E) BPA $100 \mathrm{mg} / \mathrm{L}$

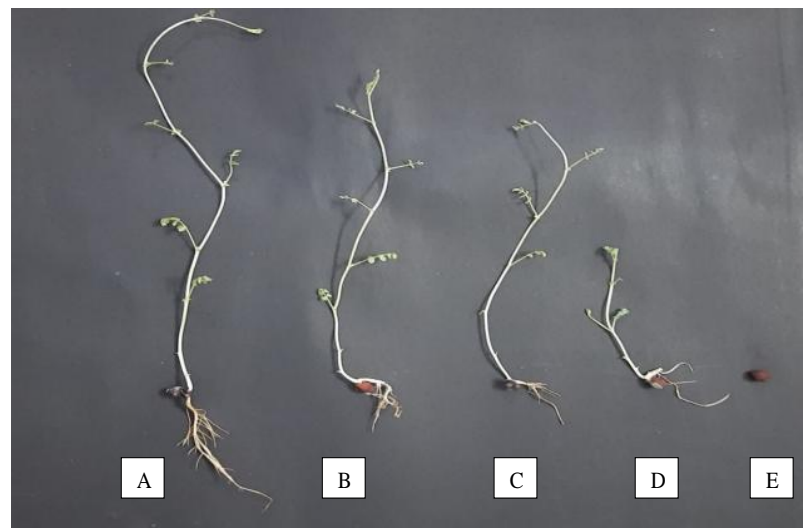


Fig.3 Effect of different concentration of BPA on root and shoot length of chickpea seedling after 21 days of exposure

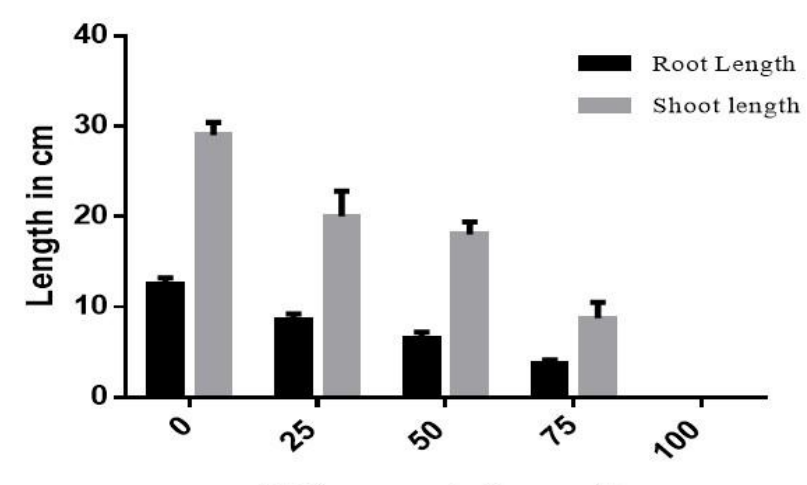

BPA concentration $\mathrm{mg} / \mathrm{L}$

Fig.4 FTIR spectra of BPA and nanoemulsion based TV laccase organogel treated BPA after 2 hours

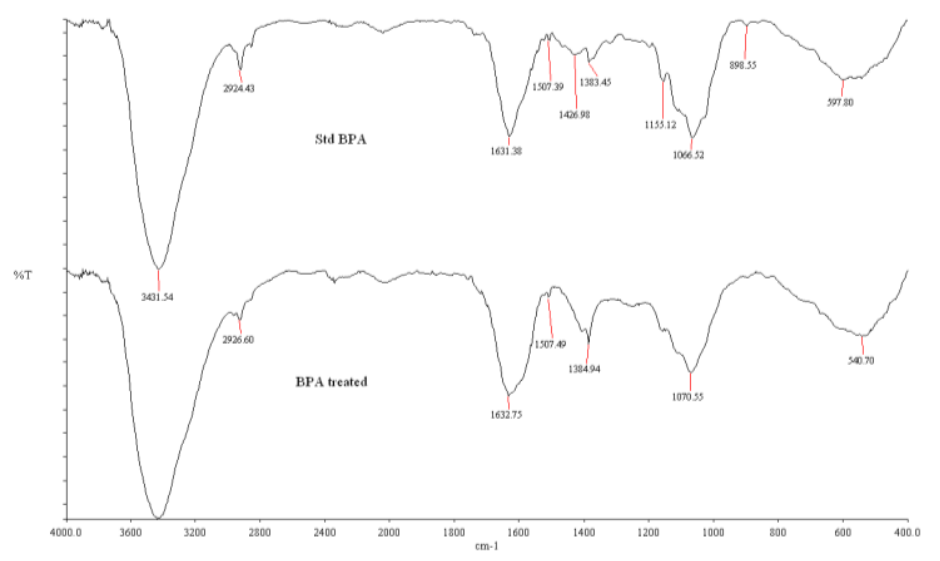

Fig.5 Effect of BPA and treated BPA on germination rate of wheat and chickpea

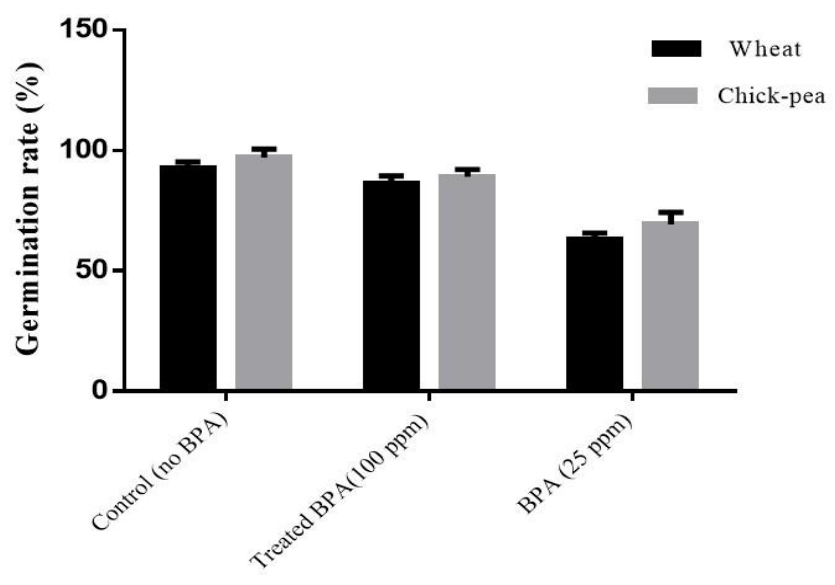


Fig.6 Effect of BPA and treated BPA solution on wheat seedling root and shoot growth after 7 , 14 and 21 days of exposure

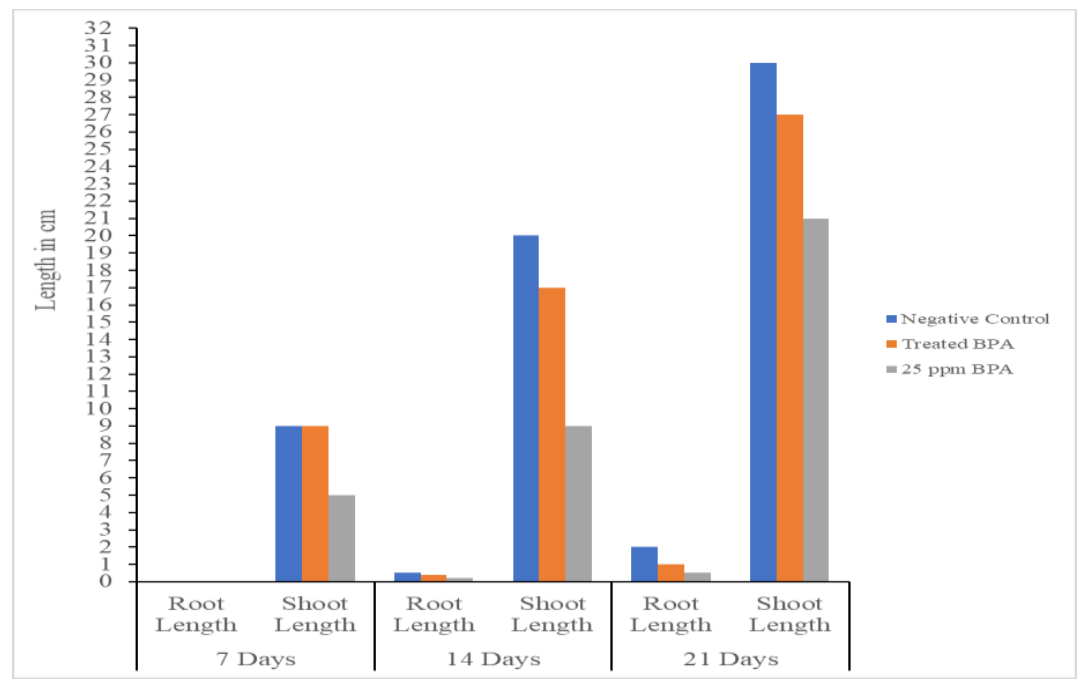

Fig.7 Effect of BPA and treated BPA solution on chickpea seedling root and shoot growth after 7,14 and 21 days of exposure

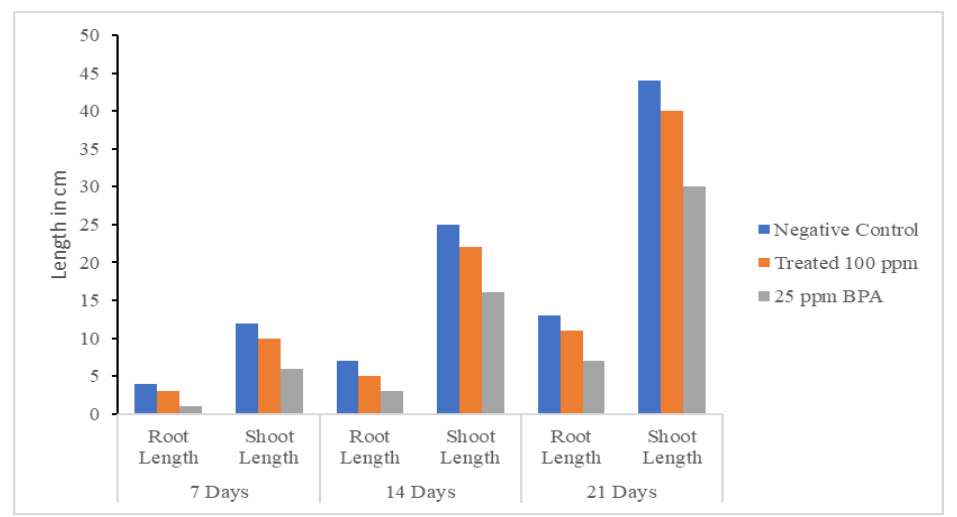

Fig.8 Effect of BPA and treated BPA solution on wheat seedling's wet and dry weight after 21 days of exposure

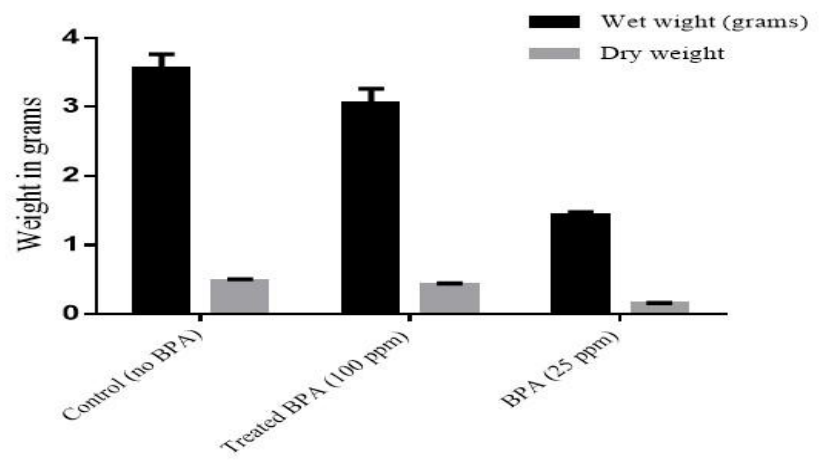


Fig.9 Effect of BPA and treated BPA solution on chickpea seedling's wet and dry weight after 21 days of exposure

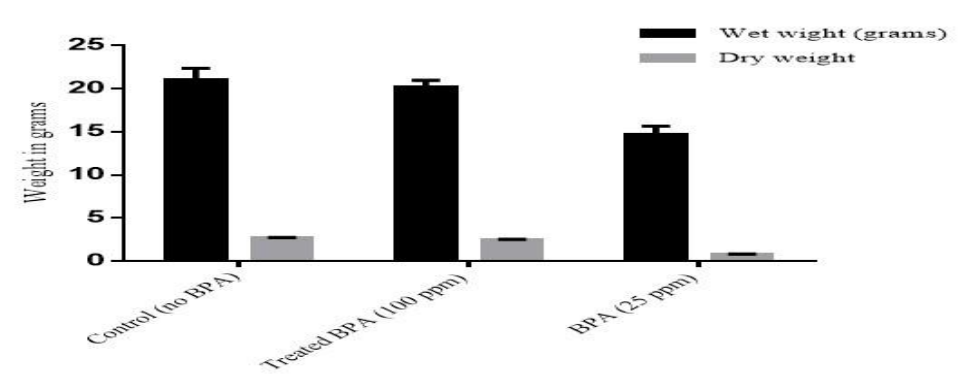

Fig.10 Comparison of mitotic index and phase index value (\%) in Allium cepa root exposed to different concentration of BPA and enzyme treated BPA after 48 hours of exposure

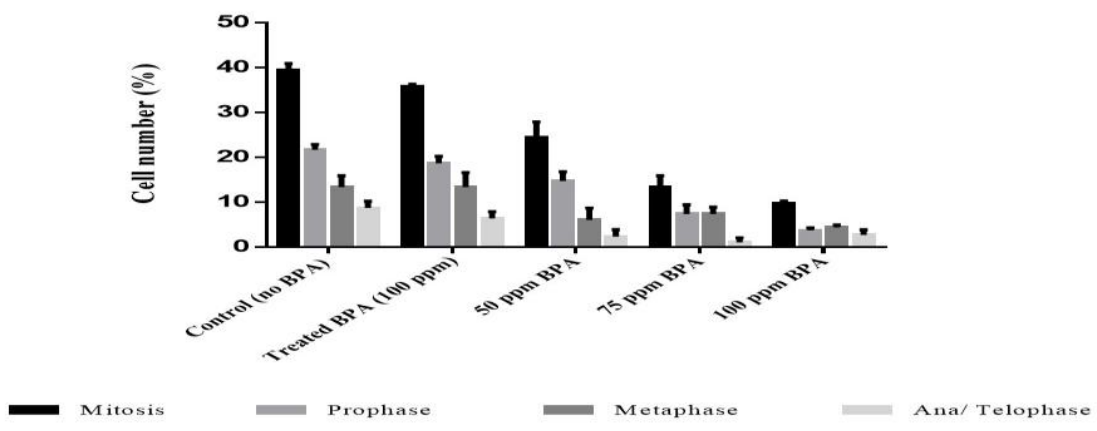

Fig.11 Clastogenic aberration induced by BPA in allium cepa root tip cells (A) normal cells showing prophase, metaphase and anaphase (B) Cells treated with bioremediated BPA solution showing normal prophase, anaphase and telophase (C,D) Binuclei formation (E,F) Anaphase bridge formation $(\mathrm{G}, \mathrm{H})$ Sticky chromosome $(\mathrm{I}, \mathrm{J})$ sticky/ distorted prophase $(\mathrm{K}, \mathrm{L})$ nuclear lesions

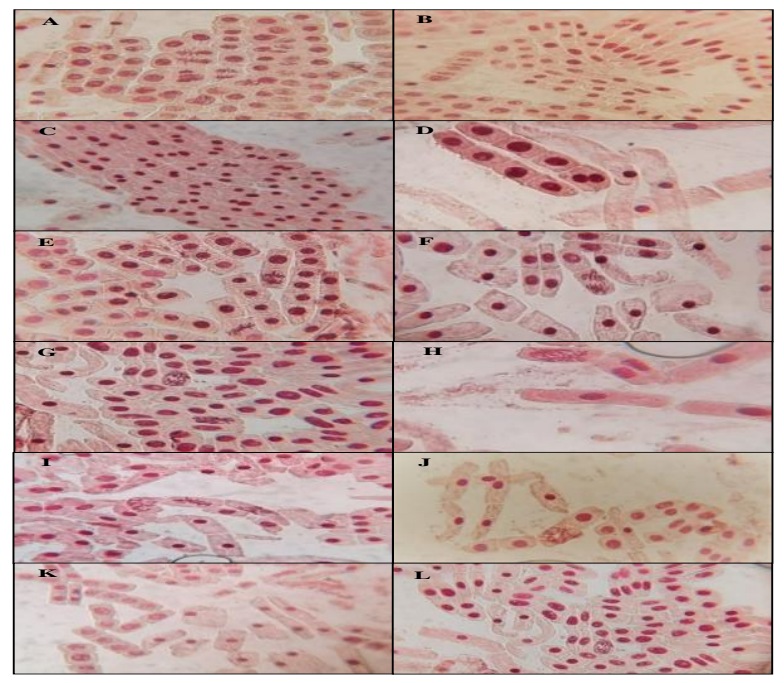


Nuclear abnormalities in the root tip include binuclei formation, sticky ana/telophase, and nuclear lesions. The root tip cells exposed to $50 \mathrm{mg} / \mathrm{L}$ BPA concentration showed binuclei formation in significantly higher number and many of the cells showed ana/telophase sticky chromosome formation. Moreover, $50 \mathrm{mg} / \mathrm{L}$ BPA showed maximum abnormalities among all varied concentration BPA treatment given. Nuclear abnormalities at 75 and $100 \mathrm{mg} / \mathrm{L}$ of BPA concentration were found to be 15 and $8 \%$ respectively. The mitotic index was 38 and $20 \%$ at 75 and $100 \mathrm{mg} / \mathrm{L}$ BPA concentration respectively which showed sub lethal and lethal effect on test plant Allium cepa cells. It is evident that $50 \mathrm{mg} / \mathrm{L} \mathrm{BPA}$ affects various stages of cell cycle and induce chromosome and nuclear abnormalities, but higher concentration of this chemical caused reduction of mitosis in root tip cells.

The plant species included in this study are sensitive towards BPA exposure. It induces phytotoxic and clastogenic effect in concentration above $25 \mathrm{mg} / \mathrm{L}$. There are some reports which reveals that low BPA concentration promotes plant growth but BPA in moderate and high concentration (6 to 12 $\mathrm{mg} / \mathrm{L}$ ) inhibits root growth in some plants including soybean seedling (Sun et al., 2012). The inhibitory effect of BPA on root and shoot growth may be due to disturbed endogenous hormones level, BPA may decreased amount of indole acetic acid (IAA) and gibberellic acid $3\left(\mathrm{GA}_{3}\right)$ as well as increase in ethanol and abscisic acid in plant system. As IAA and $\mathrm{GA}_{3}$ play key role in cell division and cell growth, reduction in root and shoot length can be observed (Li et al., 2018). Moreover, negative effect of BPA also has been noted on the growth of tomato, durum wheat and lettuce grown hydroponically, and the cytotoxic effect was correlated with BPA absorption from growth medium (Ferrara et al., 2006).
According to Dogan et al., (2010) chickpea germination was not significantly affected in presence of 10 and $50 \mathrm{mg} / \mathrm{L}$ BPA, but germination was totally inhibited at $100 \mathrm{mg} / \mathrm{L}$ BPA concentration, which is consistent with our findings. There are some reports which suggest that BPA increases membrane permeability of root cells and induces stress in plants which leads to higher production of reactive oxidation species (ROS), such condition may negatively affect plant growth. Increased ROS production has been noted in rice seedlings due to exposure of BPA greater than $10 \mu \mathrm{M}$ concentration and it was corelated with reduced organelle growth (Ali et al., 2016).

The results obtained from Allium cepa assay indicate severe clastogenic and cytogenic effect of omnipresent pollutant BPA. The mitotic index endpoint is considered to reliably identify the presence of cytotoxic pollutant present in the environment. A $50 \%$ reduction in mitotic index as compared to control suggest sublethal effects on test plant. Mitotic index below 22\% indicates lethal effect of pollutant on test plant (Mesi and Kopliku, 2013). In this study, BPA decreases mitotic index significantly in dose dependent manner. Mitotic index reduction by $50 \%$ is noted at BPA concentration between 50 and $75 \mathrm{mg} / \mathrm{L}$ in present study which suggest that this concentration is sub lethal to test organism and $100 \mathrm{mg} / \mathrm{L}$ BPA concentration poses lethal effect on Allium cepacells. BPA induced chromosomal aberration whichare observed during various phases of mitosis (binuclei formation, sticky ana/telophase) may be due to disturbance in microtubule organization (Adamakis et al., 2019;Prajitha and Thoppil, 2016).This aberration may result due to chromatin dysfunction or spindle failure (Leme and Marin-Morales, 2009). The presence of sticky chromosome was prominent in cells treated with BPA in all concentration indicating its clastogenic 
effects, this aberration may result in atypical metaphase and anaphase. Increased stickiness may lead to formation of sticky bridge during mitotic phases prevents normal cytokinesis (Radic et al., 2010; Mesi and Kopliku, 2013).

As the BPA concentration increase beyond 50 $\mathrm{mg} / \mathrm{L}$ concentration there was a decline in cells having chromosomal aberration and binuclei formation. This may be due to the phenomenon that higher amount of BPA showed higher cytotoxic effects and totally inhibiting mitosis in early stage and may lead to cell death, the reduction in mitotic index and reduced root length are also consequences of this effect.

The lateral root development process was also hindered suggesting that this chemical have inhibitory effect on zone of division, zone of elongation and zone of maturation of developing root system.

There was no evident phytotoxic and clastogenic effect noted in Allium cepa cells provided with laccase nano emulsion based organogel treated $100 \mathrm{mg} / \mathrm{L}$ BPA solution; all growth indices and mitotic index was almost like control experiment. These findings suggest that there is considerable reduction in BPA cytotoxicity after bioremediation mediated by Trametes versicolor laccase enzyme. Reverse micelles based non aqueous systems have been successfully employed for bioremediation of BPA. Laccase from Trametes versicolor encapsulated in the reverse micelles system immobilized in organogel effectively catalyses the oxidation reaction of Bisphenol A in isooctane: AOT based system. Laccase in the reverse micelles system exhibited a high and stable enzymatic activity, and better catalytic efficiency than laccase in aqueous media (Ingale et al., 2015). According to Michizoe et al., (2001) AOTlaccase reverse micelles system was able to remediate bisphenol A effectively into 4- isopropylphenol and 4-isopropenylphenol. Bioremediation of BPA using laccase is highly effective for the reduction of its toxicology. BPA oxidation using laccase generates phenoxy radicals, and these BPA oligomers lacks structural attributes necessary to bind with hormone receptor (Fang et al., 2001; Tsutsumi et al., 2001). Laccase mediated BPA oxidation leads to formation of oxidized products which are structurally different and now they are not able to work as hormone analogue and unable to induce related effects in plant system.

The findings of this study clearly indicate hazardous effect of BPA on Triticum aestivum, Cicer arietinum and Allium cepa species and suggest that it may impose negative impact on important agricultural crops due to its mutagenic endocrine disrupting properties. Remediation of this contaminant is very much important for the protection of entire ecosystem. Laccase mediated non aqueous catalysis have found to be promising approach to eliminate hazardous effect of environmental pollutant BPA.

In conclusion the BPA is omnipresent endocrine disrupting chemical of high concern due to its adverse effect on ecosystem. Present study confirms phytotoxic and clastogenic effect of BPA on Triticum aestivum, Cicer arietinum and Allium cepa plant species. Industrial wastewater and agricultural fields contaminated with BPA have disastrous effect on plant system. Looking at the brighter side, laccase treatment was very efficient in terms of nullifying the phytotoxicity up to certain extent and clastogenic effect completely induced by BPA. Thus, considering low solubility of BPA in aqueous system Trametes versicolor laccase nanoemulsion based organogels are proved to be efficient system to carry out nonaqueous catalysis and reducing its hazardous effect significantly. 


\section{References}

Adamakis, I-D.S., Panteris, E., and Eleftheriou, E.P., 2019. Tubulin Acetylation Mediates Bisphenol A Effects on the Microtubule Arrays of Allium cepa and Triticum turgidum. Biomolecules. 9 , 185. https://doi.org/10.3390/biom9050185

Ali, I., Liu, B., Farooq, M.A., Islam, F., Azizullah, A., Yu, C., Su, W. and Gan, Y. 2016. Toxicological effects of bisphenol A on growth and antioxidant defense system in Oryza sativa as revealed by ultrastructure analysis. Ecotoxicol. Environ. Saf. 124, 277-284. https://doi.org/10.1016/j.ecoenv.2015.1 0.027

Chhaya, U., and Gupte, A., 2013. Possible role of laccase from Fusarium incarnatum UC-14 in bioremediation of bisphenol A using reverse micelles system. J. Hazard. Mater. 254-255, 149-156.

https://doi.org/10.1016/j.jhazmat.2013.0 3.054

Corrales, J., Kristofco, L.A., Steele, W.B., Yates, B.S., Breed, C.S., Williams, E.S., and Brooks, B.W.2015. Global Assessment of Bisphenol $\mathrm{A}$ in the environment. Dose-Response. 13, 155932581559830.

https://doi.org/10.1177/1559325815598 308

Crain, D.A., Eriksen, M., Iguchi, T., Jobling, S., Laufer, H., LeBlanc, G.A., and Guillette, L.J. 2007. An ecological assessment of Bisphenol-A: Evidence from comparative biology. Reprod. Toxicol. 24, 225-239. https://doi.org/10.1016/J.REPROTOX.2 007.05.008

Dogan, M., Yumrutas, O., Saygideger, S.D., Korkunc, M., Gulnaz, O. and Sokmen, A. 2010. Effects of Bisphenol A and Tetrabromobisphenol A on chickpea roots in germination stage. Am. Eurasian J. Agric. Environ. Sci., 9(2), 186-192.

Experts, I. 2016. Bisphenol-A Research Report | BPA Market Research Report. https://industry-

experts.com/verticals/chemicals-andmaterials/bisphenol-a-a-global-marketoverview. Accessed 06 Jan 2021

Fang H., Tong W, Shi L.M., Blair, R., Perkins, R., Branham, W., Hass B.S., Xie Q., Dial S.L., Moland C.L. and Sheehan D.M. 2001. Structure Activity relationships for a large diverse set of natural, synthetic, and environmental estrogens. Chem. Res. Toxicol. 280-294. https://doi.org/10.1021/tx000208y

Ferrara, G., Loffredo, E., andSenesi, N. 2006. Phytotoxic, clastogenic and bioaccumulation effects of the environmental endocrine disruptor bisphenol $\mathrm{A}$ in various crops grown hydroponically. Planta. 223, 910-916. https://doi.org/10.1007/s00425-0050147-2

Fiskesjo, G. 2008. The Allium test as a standard in environmental monitoring. Hereditas. 102, 99-112. https://doi.org/10.1111/j.16015223.1985.tb00471.x

Frejd, D., Dunaway, K., Hill, J.,Van Maanen, J., and Carlson, C.2016. The Genomic and morphological effects of Bisphenol A on Arabidopsis thaliana. PLoS One. 11 , $\mathrm{e} 0163028$. https://doi.org/10.1371/journal.pone.016 3028

Ingale, S.S., Joshi, R., and Chhaya, U. 2015. Optimization of Tremetes Versicolor Laccase Reverse Micelles System for the Removal of Phenolic Environmental Pollutant Bisphenol A. Int.J.Curr.Microbiol.App.Sci.4(5), 3949. http://www.ijcmas.com. Accessed 19 January 2020 
Jadhav, V.V., Jadhav, A.S., Chandagade, C.A., and Raut, P.D. 2012. Genotoxicity of Bisphenol A on root meristem cells of Allium cepa: A Cytogenetic Approach. Asian J. Water. Environ.Pollut. 9, 39-43

Kwak, H. I., Bae, M. O., Lee, M. H., Lee, Y. S., Lee, B. J., Kang, K. S., Chae, C.H., Sung, H.J., Shin, J.S., Kim, J.H., Mar, W.C., Sheen, Y.Y., and Cho M.H. 2001. Effects of nonylphenol, bisphenol A, and their mixture on the viviparous swordtail fish (Xiphophorus helleri). Environ. Toxicol. Chem. 20(4), 787795. https://doi.org/10.1002/etc.5620200414

Lee, J., Choi, K., Park, J., Moon, H. B., Choi, G., Lee, J. J., Suh E., Kim H.J., Eun S.H., Kim G.H., Cho G.J., Kim S.K., Kim S., Kim S.Y., Kim S., Eom S., Choi S., Kim Y.D., and Kim S. 2018. Bisphenol A distribution in serum, urine, placenta, breast milk, and umbilical cord serum in a birth panel of mother-neonate pairs. Sci. Total Environ. 626, 1494-1501. https://doi.org/10.1016/j.scitotenv.2017. 10.042

Leme, D.M. and Marin-Morales, M.A. 2009.Allium cepa test in environmental monitoring: A review on its application. Mutat. Res. - Rev. Mutat. Res. 682, 71 81

Li, X., Wang, L., Wang, S., Yang, Q., Zhou, Q., and Huang, X. 2018. A preliminary analysis of the effects of bisphenol A on the plant root growth via changes in endogenous plant hormones. Ecotoxicol. Environ. Saf., 150, 152-158. https://doi.org/10.1016/j.ecoenv.2017.1 2.031

Mesi, A. and Kopliku, D. 2013. Cytotoxic and genotoxic potency screening of two pesticides on Allium cepa L. Procedia Technol. 8, 19-26. https://doi.org/10.1016/j.protcy.2013.11
.005

Michizoe, J., Goto, M., and Furusaki, S. 2001. Catalytic activity of laccase hosted in reversed micelles. J.Biosci.Bioeng. 92, 67-71. https://doi.org/10.1016/s13891723(01)80201-2

Mihaich, E., Staples, C., Ortego, L., Klecka, G., Woelz, J., Dimond, S., andHentges, S. 2018. Life-cycle studies with 2 marine species and bisphenol A: The mysid shrimp (Americamysisbahia) and sheepshead minnow (Cyprinodon variegatus). Environ. Toxicol. Chem. $37(2)$, 398-410. https://doi.org/10.1002/etc.3957

Mikolajewska, K., Stragierowicz, J., and Gromadzinska, J. 2015. Bisphenol A Application, sources of exposure and potential risks in infants, children and pregnant women. Int. J. Occup. Med. Environ. Health. 28, 209-241

Pan, W. J., Xiong, C., Wu, Q. P., Liu, J. X., Liao, H. M., Chen, W., Liu S.Y., and Zheng, L.2013. Effect of BPA on the germination, root development, seedling growth and leaf differentiation under different light conditions in Arabidopsis thaliana. Chemosphere. 93, 2585-2592. https://doi.org/10.1016/j.chemosphere.2 013.09.081

Prajitha, V., and Thoppil, J.E. 2016. Genotoxic and antigenotoxic potential of the aqueous leaf extracts of Amaranthus spinosus Linn. using Allium cepa assay. South African J. Bot. 102 ,

$18-25$ https://doi.org/10.1016/j.sajb.2015.06.0 18

Radic, S., Stipanicev, D., Vujcic, V., Rajcic, M.M., Sirac, S., and Pevalek-Kozlina, B. 2010. The evaluation of surface and wastewater genotoxicity using the Allium cepa test. Sci. Total Environ.408(5), 1228-1233. https://doi.org/10.1016/j.scitotenv.2009. 11.055 
Sun, H., Wang, L., and Zhou, Q. 2013. Effects of bisphenol A on growth and nitrogen nutrition of roots of soybean seedlings. Environ. Toxicol. Chem. 32, 174-180. https://doi.org/10.1002/etc.2042 of bisphenol A and nonylphenol by oxidative enzymes from lignindegrading basidiomycetes. Chemosphere. 42, 271-276. https://doi.org/10.1016/S00456535(00)00081-3

Tsutsumi, Y., Haneda, T. and Nishida, T. 2001. Removal of estrogenic activities

\section{How to cite this article:}

Janki Trivedi and Urvish Chhaya. 2021. Evaluation of Phytotoxic and Clastogenic Potential of Phenolic Pollutant Bisphenol A and its Bioremediated Product in Triticum aestivum, Cicer arietinum and Allium cepa. Int.J.Curr.Microbiol.App.Sci. 10(02): 777-790. doi: https://doi.org/10.20546/ijcmas.2021.1002.093 